\title{
The Multilevel Effects of Creative Leadership on Employees' Workplace Innovative Behavior: An Integrated Analysis Framework
}

\author{
Xiaoqin Liu', Xiaohui Li1 ${ }^{*}$, Weizhen Chen'1, Qiaoping Yu², Shihai Lai ${ }^{1}$ \\ ${ }^{1}$ School of Business, Guangdong University of Foreign Studies, Guangzhou, China \\ ${ }^{2}$ School of Economics, Fujian Normal University, Fuzhou, China \\ Email: ${ }^{\star 505381026 @ q q . c o m ~}$
}

How to cite this paper: Liu, X. Q., Li, X. H., Chen, W. Z., Yu, Q. P., \& Lai, S. H. (2020). The Multilevel Effects of Creative Leadership on Employees' Workplace Innovative Behavior: An Integrated Analysis Framework. Open Journal of Social Sciences, 8, 295-307.

https://doi.org/10.4236/jss.2020.812024

Received: November 20, 2020

Accepted: December 21, 2020

Published: December 24, 2020

Copyright $\odot 2020$ by author(s) and Scientific Research Publishing Inc. This work is licensed under the Creative Commons Attribution International License (CC BY 4.0).

http://creativecommons.org/licenses/by/4.0/

\begin{abstract}
Workplace innovation is a hot issue that has been concerned with organizational innovation research. Based on the theory of self-determination and regulatory focus, this research systematically analyzes the mechanism and boundary conditions of the creative leadership to employees' workplace innovative behavior from a practical point of view, and constructs a new integrated analysis framework. Among this framework, creative leadership affects employees' workplace innovative behavior respectively through the individual level and team level by regulatory focus, thriving, and team innovative climate, while creative self-efficacy and team innovative climate moderated the relationship of different stages between creative leadership and employees' workplace innovative behavior.
\end{abstract}

\section{Keywords}

Creative Leadership, Innovative Behavior, Regulatory Focus, Thriving, Innovative Climate

\section{Introduction}

Nowadays the process of economic globalization is accelerating and has become an irresistible trend. Meanwhile, the world economy remains sluggish with increasing uncertainties; the wealth gap and North-South gap are outstandingly widening. The first significant step to address these problems is insisting on the strategy of innovation-driven development and creating a vigorous economic growth pattern. To implement the above measures, people must be regarded as the starting point and standpoint of all work; therefore only by cultivating and 
bringing up a large number of employees with excellent innovative consciousness and innovation ability can the organization better cope with today's changing complex environment. In the traditional view, leadership signifies the position of authority, the execution of functions, and the delegation of tasks within the structure of organizational hierarchy; and according to the modern concept, leaders focus more on the avoidance of decision risks and the effective management and utilization of organizational resources so as to further promote the sustainable growth of the organization. However, in this era of great change, it's the primary mission of organizational leaders to continuously observe, interpret, adjust and adapt to the constantly changing environment, and those organizations led by insensitive leaders who enjoy safety and comfort in certain and stable environment are bound to fall into predicament and doomed to decline (Hon et al., 2014). As a result, the survival and development of organizations in the background of globalization depends crucially on the ability of leaders to effectively predict and proactively drive changes, that is, on their innovation ability. The innovation ability is no longer a secondary option when selecting the traditional important leadership skills, but a core necessity of the most important priorities. Creative leadership is the certain and decisive factor that leads organizations out of predicament and recreates brilliance in the era of digital economy and innovation economy (Banerjee et al., 2016). In the face of changes and uncertainties, organizational leaders should not only be adept in innovative thoughts and innovation action, but also be proficient in arousing and integrating the innovative consciousness and innovation ability of others. Therefore, this research focuses on the following questions: What is creative leadership? What is the mechanism and boundary conditions of the creative leadership to employees' workplace innovative behavior?

\section{Literature Review}

Creativity is both conceived of as the first stage (Anderson et al., 2014) and an important part of innovation. Thus, this research will define core concepts, clear research thoughts and build theoretical models based on literature on creativity and innovation.

\subsection{Creative Leadership}

Creative leadership has a long and interesting history in Organization Theory. The sustainable development of those organizations with uncertainty and relative freedom is in great need of creative leadership (Selznick, 1984). Leading innovative pursuits requires a unique set of leadership behavior that are frequently at odds with traditional forms of management and organizational functioning (Hunter et al., 2011), but never before has the development of human society required creative leadership (Tierney et al., 2010). Creative leadership calls for the art of system construction that are novel but consistent, and the creation and maintaining of those conditions that are denied now but may become reality in 
the future. Mumford et al. (2002) suggested that creative leadership differs from other forms of leadership in three ways: The first way, the leadership of creative ventures differs from the nature of the work to be done. Earlier, we noted that creative efforts, by definition, present novel, ill-defined tasks. The leader, as a result, cannot rely on predefined structures but, instead, must be capable of inducing structure and providing direction to work where there is no inherent direction. Another way creative leadership differs from leadership in other domains pertains to the effective exercise of influence. By virtue of the autonomy, professional focus, intrinsic motivation, and critical orientation, the leader of creative people cannot rely on position power, conformity pressure, and organizational commitment as vehicles for directing the work. Indeed, such actions are likely to prove counter productive by inhibiting requisite exploration. To complicate matters further, creative people will be working on risky, demanding tasks where success is by no means assured. These observations, in turn, imply that, in directing the people and directing the work, different influence tactics will be required than those applied in other settings. A third way creative leadership differs from other leadership endeavors derives from the inherent conflict between innovation and organization. Innovation is an expensive, inherently risky, venture in any organizational setting. Organizations, however, must produce as well as explore. These characteristics of organizations and innovation result in an inherent tension between creative efforts an organizational demand. As occupants of boundary role positions, the leaders of creative ventures must manage organizational relationships in such a way as to promote innovation.

Based on present studies, Wei (2012) pointed out that creative leadership refers to the process in which a leader uses creative thinking, adopts creative strategies, and provide supportive environments to enable employees to spontaneously and creatively solve problems and ultimately achieve organizational goals. Besides, Banerjee et al. (2016) claimed that innovative leaders, who choose and shape the future of their organizations instead of managing and solving problems with regulations, must first have the vision and ability of innovation for not only promoting their own innovation activities but also those of members' and organizations'. Therefore, creative leaderships show the characteristics of building heterogeneous teams, constructing culture of innovation, coordinating organizations and departments and finding solutions for decision deadlocks.

Though a considerable amount of literature has been published on creative leadership, there is still a lack of necessary theoretical support and empirical test for further researches. After a review of 752 articles across 10 top-tier academic publishing outlets, Dinh et al. (2014) pointed that creative or creative leadership has been attached great attention and investigated over the last decade, but there are still great mismatches between its theoretical deduction and practical tests. No single manifestation and practice can be the only presence as creative leadership in the real world. Therefore, Mainemelis et al. (2015) reviewed the dispersed body of knowledge and synthesized it under a global construct of creative leadership, and ultimately classified three more narrow conceptualizations: faci- 
litating employee creativity; directing the materialization of a leader's creative vision; and integrating heterogeneous creative contributions. Banerjee et al. (2016) further argued that creative leadership is a kind of mode and mentality, and also the maximization of organizational innovation ability. We move forward on the basis of the above literature to make a more specific definition of creative leadership, especially those under different cultural backgrounds.

\subsection{Creative Leadership and Employees' Workplace Innovative Behavior}

Much of the published literature on creative leadership is still basically at the stage of theoretical exploration, so there are not too many relevant researches on the relationship and mechanism between creative leadership and employees' workplace innovative behavior. Even if there are, scholars only explored their researches from the perspective of leaders' support and promotion rather than the perspective of leaders' guidance and coordination.

\subsubsection{At Individual Level}

Employees who perceive leaders' support in innovation attempts behave more expressive and have more high-performance in innovation practice (Liu et al., 2016). By supporting innovation, empowering and challenging employees, leaders can inspire their creativity and promote exploratory thinking, for psychological empowerment functions as a mediator variable (Gumusluoglu \& Ilsev, 2009). Shin and Zhou (2003) emphasized employees' motivation is an important factor influencing their workplace creativity and innovation behavior, and the support of superiors for workplace innovation can effectively inspire employees' internal working motivation, so as to improve their workplace innovation behavior. Besides, Gong et al. (2009) added that creative self-efficacy has a mediating effect between innovation-supported leaders and employees' innovative behaviors in the workplace. Other studies, from the perspective of individual, have demonstrated mediating role of pressure and friendship help between transformational leadership and employees' creativity (Ding et al., 2010; Cai, 2015). In addition, some scholars have conducted theoretical derivation and empirical tests on the regulatory role between psychological empowerment and creative self-efficacy (Pieterse et al., 2010; Qu \& Kang, 2014).

\subsubsection{At Team Level}

Si and Wei (2012) found that the team empowerment climate is positively correlated with employees' innovation performance, and moderates the relationship between innovation-supporting leadership and employees' innovation performance. In a low-level empowerment climate, leaders who support employees' innovation have a greater impact on the innovative behavior of their subordinates. Innovative climate plays a mediating role between transformational leadership and employees creativity; and transformational leadership can improve employees' creative behavior and performance by cultivating innovation climate, while employee creative self-efficacy has a moderating effect between innovation 
climate and employees creativity (Jaiswal \& Dhar, 2015). Wang \& Rode (2010) put forward a theoretical hypothesis that innovative climate moderates the relationship between transformational leadership and employee creativity such that the relationship will be weaker under a high creative climate than under a low creative climate. However, this hypothesis is not supported by empirical result.

\subsubsection{At Organizational Level}

A key study by Sattayaraksa and Boon-itt (2016) concluded that organizational learning and innovative culture are two mediating variables between transformational leadership and employee creativity, and leaders support new product development by organizational learning and innovative culture. Transformational leadership can positively influence employees' workplace innovative performance through the organizational innovative climate (Chen \& Hou, 2016; Jung et al., 2016). However, employees' perceived hierarchy climate has the opposite effect and organizational scale can also play a mediating role in that relationship (Jung et al., 2016). Transformational leadership positively impact on employee innovative behavior through organizational innovative climate and LMX average (Huo \& Luo, 2011).

\subsubsection{At Other Level}

Jung et al. (2008) provided an exploratory analysis that employees' perception of the uncertainty from the external environment plays a moderating role between creative leadership and employees' innovative behavior. It is such complicated mechanism how creative leadership impact on employees' innovation that many factors must be taken into account to achieve a more comprehensive and deeper understanding.

\subsection{Literature Comments}

Although existing studies have made great contribution to the research of creative leadership and its effect on employees' workplace innovative behavior, there are still three gaps to be addressed.

Firstly, it's proposed to classify the conceptualization of creative leadership and construct its measuring scale. Most of the early literatures on creative leadership are limited by different specialties or research fields, and most of them are tentative explorations in theories. So what exactly is creative leadership? Can the leadership that promotes the creativity or innovation of employees be called creative leadership? Gurd \& Helliar (2017) pointed that creative leadership is a very complex activity, which needs more detailed theory combing, concept definition and more specific practical verification.

In addition, there is a need to further classify and define different employees' workplace innovative behavior. Innovation has long been defined as the generation of novel and practical ideas related to products, services and processes, and is often used as a one-dimensional concept in research. But in fact, using such ambiguous concept may lead to bias and fail to contribute a scientific conclu- 
sion. Because innovative behaviors (i.e. ground-breaking innovative behavior, gradual innovative behavior and deviant innovative behavior) differentiate in characteristics, focuses and uncertainties, which implies diverse mechanisms of occurrence and influence.

Lastly, researches on influence mechanism of creative leadership are narrow in approaches, piecemeal in results and unsystematic in framework, thus it's a great necessity to hackle and combine the existing results. There are three main factors influencing employees' workplace innovative behavior: people, process and environment. They are independent of each other and influence each other to promote employees' innovation in a coordinated way. However, the substantial differences between leaders and employees, between extrinsic motivations and intrinsic psychology, and between situations are neglected by a majority of existing studies and are separated into individual researches without enough consideration given to the exploration of comprehensive influence mechanisms.

\section{Research Ideas and Theoretical Framework}

Innovation is regarded by modern organizations as an important means of adapting to the changing environments to improve their products, services, and processes. And in reality, innovation is driven by the coordination of individual characteristics, psychological activities, working environment and other factors. However, those correlated variables are studied in isolation from each other. Most of the existing studies fail to accurately grasp the dynamic characteristics of internal psychological processes and interpersonal interaction processes related to the impact of creative leadership on employees' workplace innovative behavior (Dinh et al., 2014). Thus, researchers should adopt a comprehensive framework for further study of workplace innovation rather than isolating individual and contextual factors from each other (Anderson et al., 2014). To respond to this appeal, this research is to integrate self-determination theory and regulatory focus theory to explain how individual characteristics and working situations collaboratively affect employees' emotion and motivation, thus promoting their innovative behavior. Figure 1 shows the theoretical framework and research content of this study.

\subsection{Creative Leadership and Employees' Innovative Behavior: Definition and Measuring Based on Realistic Situation}

As what have been mentioned in literature review, the definition and connotation of creative leadership remain unclear and there is a lack of empirical survey scale. Besides, what employees' workplace innovative behavior exactly refers to is too general, thus being used as a one-dimensional concept. Therefore, the first objective of this research is to redefine the concept of creative leadership and develop corresponding scale according to organizational practice. Based on actual situation, employees' workplace innovative behavior can be classified into differentiated types with different levels of difficulty, uncertainties, focus and effects, rather than a one-dimension concept (Madjar et al., 2011; Mainemelis, 


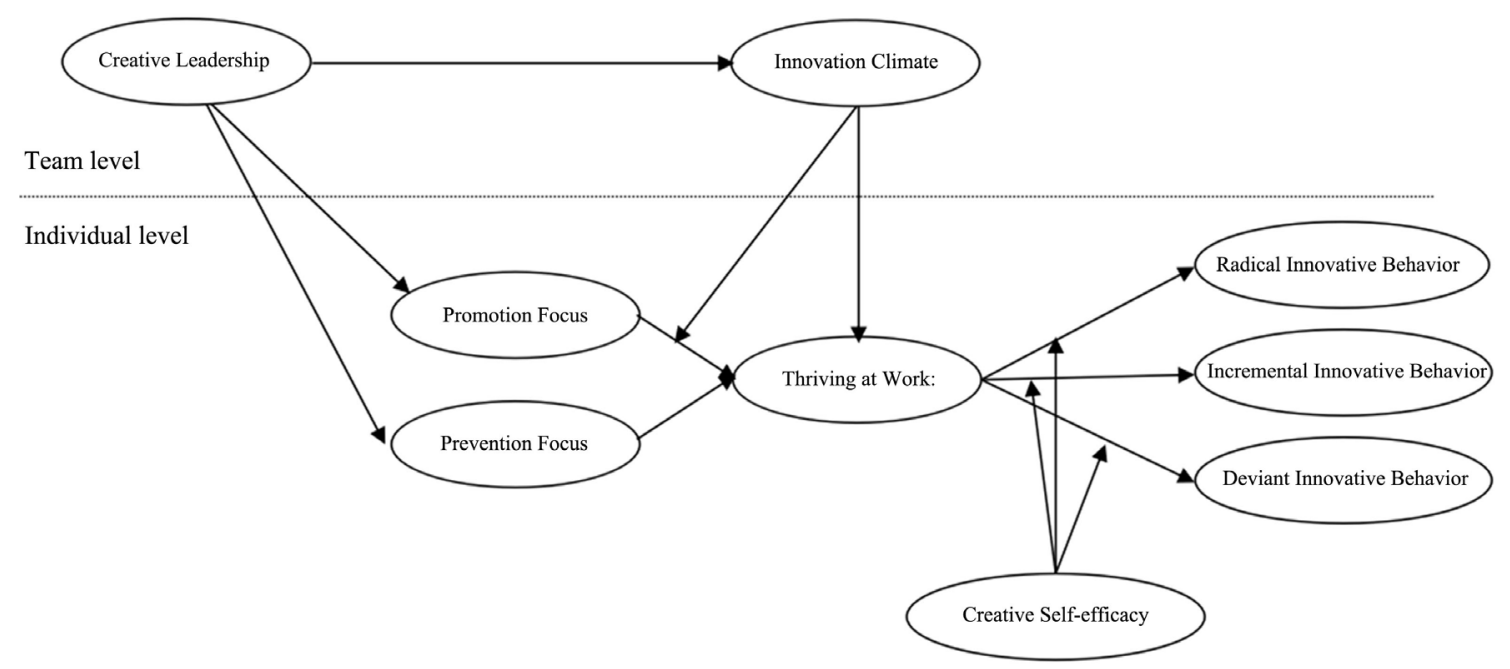

Figure 1. Theoretical framework and research content of this study.

2010). So we subdivide the concept of employees' workplace innovative behavior into radical innovative behavior, incremental innovative behavior and deviant innovative behavior. We define radical innovative behavior as ideas that differ substantially from an organization's existing practices. Highly radical ideas should suggest new and set-breaking frameworks or processes. Incremental or "adaptive" ideas, on the other hand, imply few changes in frameworks and offer only minor modifications to existing practices and products. Deviant innovative behavior refers to the behavior of employees who continue to pursue new ideas in direct violation of the instructions of their superiors.

\subsection{Creative Leadership and Employees' Innovative Behavior: From the Perspective of Individual Psychological Process}

How does creative leadership affect employees' workplace innovative behavior at the individual level? Previous researches have explored the mediating variables between them at the individual level but still haven't illuminated its underlying psychological process. Employees' self-regulatory focus is considered a mediator in the relationship between creative leadership and workplace innovative behavior (Kark \& Van Dijk, 2007), as leaders influence employees' behavior by guiding promotion focus (focusing on developmental needs and goals associated with the ideal self) and prevention focus (emphasizing safety needs and goals associated with the supposed self) according to the theory of regulatory focus (Neubert et al., 2008). Referring to other literature, we propose that thriving is also one of its crucial mediator, because thriving is essentially self-regulation, which can be cultivated, shaped and influenced by some stable personal characteristics like regulatory focus. Thriving conveys positive effects and emotion, when an individual is in the state of thriving, he or she will be more energetic and motivational to conceive and implement innovation. Therefore, the second main content of the subsequent study is to try to explore and explain this internal psychological mechanism. 


\subsection{Creative Leadership and Employees' Innovative Behavior: From the Perspective of Team Innovative Climate}

How does creative leadership affect employees' workplace innovation at the team level? Existing studies indicate that a good working environment can promote employees' self-determination and assertiveness (Krabbenborg et al., 2017). Consistent with this, we assert that team innovative climate, also as a key situational factor, can satisfy the needs of some employees in terms of freedom, ability and relationship. Once satisfied, employees are more likely to engage in those activities that ultimately lead to greater psychological growth and development. That means higher possibility of thriving and further innovation, which is core of self-determination theory. Team innovative climate takes effect more effectively at lower organizational level because organizational managers can provide closer guidance and supervision for employee participation (Parke \& Seo, 2016), considering the overall effectiveness of the team innovative climate. Since the role of creative leadership in the formation of the team innovative climate is crucial and irreplaceable, so the third main content of the subsequent study will seek to examine the mediating effect of innovative climate among creative leadership, thriving and employees' workplace innovative behavior.

\subsection{Creative Leadership and Employees' Innovative Behavior: Based on the Moderating Effect of Individual and Team Contexts}

What are the different influences of creative leadership on employees' workplace innovative behavior in different individual and team contexts? First of all, team innovative climate is likely to play a moderating role between promotion focus and thriving. This is because, for those employees with high promotion focus, high team innovative climate can provide opportunities for them to achieve work performance, which is in accordance with the mentality of promotion focus and self-motivation obtaining, to realize a fuller sense of workplace presence and work experience (Lanaj et al., 2012). Secondly, this research will try to examine the moderating effect of individual creative self-efficacy between thriving and employees' workplace innovative behavior. Though employees' creative self-efficacy has a significant mediating effect on predicting employees' workplace innovative behavior, some scholars suggested that researches should be carried out on the interaction of creative self-efficacy in predicting innovative behavior, since a firm belief o creative self-efficacy effectively motivate employees to pursue innovative behavior (Richter et al., 2012). To respond to that appeal and address the gap, the fourth main content of the subsequent study is to investigate the moderating effect of creative self-efficacy on the relationship between thriving and employees' workplace innovative behavior.

\section{Discussion}

\subsection{Research Significance}

This paper, differentiating from most existing studies for theoretical exploration, 
intends to use the sample of Chinese innovative enterprises to examines the influence mechanism of creative leadership on employees' innovative behavior in the workplace. And the academic value lies on the following aspects. First of all, it further clarifies the definition and connotation of creative leadership, provides an explicit conceptual tool for future researches, and reveals new highlights of the connotation paradox of creative leadership by emphasizing its contextual sensitivity. Second, it responds to the appeals for using cross-level methods to integrate personal factors and situational factors to predict innovative behavior more accurately and adds corresponding theoretical derivation and empirical test for it. Third, this paper can further deepen the existing researches of creative leadership and employees' innovative behavior through the empirical test and the result analysis of the mediating mechanism when predicting employees' innovative behavior influenced by creative leadership at individual level and team level.

Besides, this work generates practical application value concerning current social background and realistic demand. On one hand, by constructing a systematic analysis framework and adopting scientific methodology, it offers important insights and suggestions for the transformation and sluggish-growth problem of Chinese enterprises under the globalization predicament. On the other hand, it is hoped that this research, with an advanced understanding of the theory of creative leadership, will provide beneficial reference for enterprises to recruit and select innovative leaders who lead the business out of trouble. Another major value is that this study contributes to measures and suggestions on how to stimulate and manage employees' valuable innovative behavior in workplace, after empirical test of the cross-level influence mechanism of creative leadership on employees' workplace innovative behavior.

\subsection{Research Innovation}

In terms of academic thought, this research responds to the academic circle's call for integrating individual and situational factors to more accurately predict innovative behavior, and increases the corresponding theoretical derivation and empirical test. Although core concepts have been proved to be independently associated with innovation, few scholars adopt an inter-hierarchy approach to integrate all those variables into a study. Therefore, this paper advances previous researches and demonstrates a clearer process of how related concepts influencing and coordinating each other to promote employees' innovative behavior in the workplace.

From the perspective of academic viewpoint, we suggest that individual and situational factors should be integrated for better understanding of how creative leadership affects employees' innovative behavior in workplace. So mediator variables (regulatory focus, thriving, and team innovative climate) and moderator variables (creative self-efficacy and team innovative climate) at both individual and team level are used in this paper to outline the relationship of variables with 
newer boundary conditions and perspective. And it generates fresh and further insights into creative leadership and employees' workplace innovative behavior.

In view of research methods, researchers have implicitly adopted different visual definition standards due to the lack of normative foundation, leading to the confusion of related researches and the proliferation of research terms and branches. Those approaches are not conducive for further research of creative leadership and employee workplace innovative behavior, thus we aim to advance closer to forefront of enterprise innovation, redefine core concepts with grounded theory, and mainly use hierarchical linear model for data verification and analysis.

\section{Summary}

From the perspective of the self-determination theory and regulatory focus theory, this research explores how creative leadership influences employees' workplace innovation behavior within an integrated analysis framework. Based on theoretical review of previous research, we will redefine the concept of creative leadership. Then according to the above two theories, we construct a model of how creative leadership integrates various factors and its effects on employees' workplace innovative behavior at individual level and team level. At last that cross-level mechanism is tested in practice. To be more specific, this research sets out to achieve the following goals. Firstly, it is designed to construct a normative framework for creative leadership in order to better distinguish the relevant concepts in theoretical and empirical analysis, and to better integrate the antecedents and results of past, present and future researches of creative leadership behavior. Secondly, we attempt to establish a theoretical model of the cross-level influence mechanism of creative leadership on employees' workplace innovative behavior, and intend to obtain first-hand data for empirical tests through interviews and questionnaires to ensure the matching ability between theory and practice. Thirdly, based on the first two objectives, we intend to provide specific recommendations for those organizations that seek to inspire, use, regulate and manage "creative leadership" and "innovative behavior in the workplace".

Though research suppositions and expected goals are exciting, there are also likely to be some hurdles to overcome. For one thing, it is really a heavy workload to read a large number of domestic and foreign literature related to creation and innovation, when determining the theoretical support, normative definition and framework of creative leadership and employees' workplace innovative behavior. For another thing, it is necessary to find reasonable theoretical support and explanation for the dynamic relationship between creative leadership of different dimensions and innovative behavior of different types of employees during theoretical construction and practical test. Besides, it is an extreme hardship to ensure the research is scientific and normative when completing data matching, on-site interview or longitudinal survey. 


\section{Supported}

This research was supported by the National Social Science Fund of China (project number: 17BGL095).

\section{Conflicts of Interest}

The authors declare no conflicts of interest regarding the publication of this paper.

\section{References}

Anderson, N., Potočnik, K., \& Zhou, J. (2014). Innovation and Creativity in Organizations: A State-of-the-Science Review, Prospective Commentary, and Guiding Framework. Journal of Management, 40, 1297-1333. https://doi.org/10.1177/0149206314527128

Banerjee, B., Ceri, S., \& Leonardi, C. (2016). Innovation Leadership: A New Kind of Leadership. In B. Banerjee, \& S. Ceri (Eds.), Creating Innovation Leaders (pp. 53-80). Cham: Springer International Publishing. https://doi.org/10.1007/978-3-319-20520-5_3

Cai, Y. H. (2015). Transformational Leadership and Employee Creativity-The Mediating Role of Pressure. Science Research Management, 36, 112-119.

Chen, A. S.-Y., \& Hou, Y.-H. (2016). The Effects of Ethical Leadership, Voice Behavior and Climates for Innovation on Creativity: A Moderated Mediation Examination. The Leadership Quarterly, 27, 1-13. https://doi.org/10.1016/j.leaqua.2015.10.007

Ding, L., Xi, Y. M., \& Zhang, H. (2010). Transformational Leadership and Employee Creativity: The Mediating Role of Supervisor-Subordinate Relationship. Science Research Management, No. 1, 177-184.

Dinh, J. E., Lord, R. G., Gardner, W. L. et al. (2014). Leadership Theory and Research in the New Millennium: Current Theoretical Trends and Changing Perspectives. The Leadership Quarterly, 25, 36-62. https://doi.org/10.1016/j.leaqua.2013.11.005

Gong, Y., Huang, J.-C., \& Farh, J.-L. (2009). Employee Learning Orientation, Transformational Leadership, and Employee Creativity: The Mediating Role of Employee Creative Self-Efficacy. Academy of Management Journal, 52, 765-778.

https://doi.org/10.5465/amj.2009.43670890

Gumusluoglu, L., \& Ilsev, A. (2009). Transformational Leadership, Creativity, Organizational Innovation. Journal of Business Research, 62, 461-473.

https://doi.org/10.1016/j.jbusres.2007.07.032

Gurd, B., \& Helliar, C. (2017). Looking for Leaders: "Balancing” Innovation, Risk and Management Control Systems. The British Accounting Review, 49, 91-102. https://doi.org/10.1016/j.bar.2016.10.008

Hon, A. H. Y., Bloom, M., \& Crant, J. M. (2014). Overcoming Resistance to Change and Enhancing Creative Performance. Journal of Management, 40, 919-941.

https://doi.org/10.1177/0149206311415418

Hunter, S. T., Thoroughgood, C. N., Myer, A. T., \& Ligon, G. S. (2011). Paradoxes of Leading Innovative Endeavors: Summary, Solutions, and Future Directions. Psychology of Aesthetics Creativity \& the Arts, 5, 54-66. https://doi.org/10.1037/a0017776

Huo, W. W., \& Luo, J. L. (2011). A Study of Cross-Level Analysis Mechanism on the Relationship between Leadership Behavior and Employee Behavior. Forecasting, 30, 42-47.

Jaiswal, N. K., \& Dhar, R. L. (2015). Transformational Leadership, Innovation Climate, 
Creative Self-Efficacy and Employee Creativity: A Multilevel Study. International Journal of Hospitality Management, 51, 30-41. https://doi.org/10.1016/j.ijhm.2015.07.002

Jung, D., Kim, Y., Suh, Y. et al. (2016). Perceived Innovation Barriers and Open Innovation Performance: Insights from Korea. International Journal of Knowledge-Based Development, 7, 125-142. https://doi.org/10.1504/IJKBD.2016.076466

Jung, D., Wu, A., \& Chow, C. W. (2008). Towards Understanding the Direct and Indirect Effects of CEO's Transformational Leadership on Firm Innovation. Leadership Quarterly, 19, 582-594. https://doi.org/10.1016/j.leaqua.2008.07.007

Kark, R., \& Van Dijk, D. (2007). Motivation to Lead, Motivation to Follow: The Role of the Self-Regulatory Focus in Leadership Processes. Academy of Management Review, 32, 500-528. https://doi.org/10.5465/amr.2007.24351846

Krabbenborg, M. A. M., Boersma, S. N., van der Veld, W. M., Vollebergh, W. A. M., \& Wolf, J. R. L. M. (2017). Self-Determination in Relation to Quality of Life in Homeless Young Adults: Direct and Indirect Effects through Psychological Distress and Social Support. The Journal of Positive Psychology, 12, 130-140.

Lanaj, K., Chang, C.-H., \& Johnson, R. E. (2012). Regulatory Focus and Work-Related Outcomes: A Review and Meta-Analysis. Psychological Bulletin, 138, 998-1034. https://doi.org/10.1037/a0027723

Liu, D., Jiang, K., Shalley, C. E., Keem, S., \& Zhou, J. (2016). Motivational Mechanisms of Employee Creativity: A Meta-Analytic Examination and Theoretical Extension of the Creativity Literature. Organizational Behavior and Human Decision Processes, 137, 236-263. https://doi.org/10.1016/j.obhdp.2016.08.001

Madjar, N., Greenberg, E., \& Chen, Z. (2011). Factors for Radical Creativity, Incremental Creativity, and Routine, Noncreative Performance. Journal of Applied Psychology, 96, 730-743. https://doi.org/10.1037/a0022416

Mainemelis, C. (2010). Stealing Fire: Creative Deviance in the Evolution of New Ideas. Academy of Management Review, 35, 558-578.

https://doi.org/10.5465/amr.35.4.zok558

Mainemelis, C., Kark, R., \& Epitropaki, O. (2015). Creative Leadership: A Multi-Context Conceptualization. The Academy of Management Annals, 9, 393-482. https://doi.org/10.5465/19416520.2015.1024502

Mumford, M. D., Scott, G. M., Gaddis, B., \& Strange, J. M. (2002). Leading Creative People: Orchestrating Expertise and Relationships. Leadership Quarterly, 13, 705-750. https://doi.org/10.1016/S1048-9843(02)00158-3

Neubert, M. J., Kacmar, K. M., Carlson, D. S. et al. (2008). Regulatory Focus as a Mediator of the Influence of Initiating Structure and Servant Leadership on Employee Behavior. Journal of Applied Psychology, 93, 1220-1233. https://doi.org/10.1037/a0012695

Parke, M. R., \& Seo, M.-G. (2016). The Role of Affect Climate in Organizational Effectiveness. The Academy of Management Review, 42, 334-360. https://doi.org/10.5465/amr.2014.0424

Pieterse, A. N., van Knippenberg, D., Schippers, M., \& Stam, D. (2010). Transformational and Transactional Leadership and Innovative Behavior: The Moderating Role of Psychological Empowerment. Journal of Organizational Behavior, 31, 609-623.

Qu, R. J., \& Kang, H. Q. (2014). The Contingent Influence of Leadership on Employee Creativity. Management Review, 26, 88-98.

Richter, A. W., Hirst, G., van Knippenberg, D., \& Baer, M. (2012). Creative Self-Efficacy and Individual Creativity in Team Contexts: Cross-Level Interactions with Team In- 
formational Resources. Journal of Applied Psychology, 97, 1282-1290.

https://doi.org/10.1037/a0029359

Sattayaraksa, T., \& Boon-itt, S. (2016). CEO Transformational Leadership and the New Product Development Process: The Mediating Roles of Organizational Learning and Innovation Culture. Leadership \& Organization Development Journal, 37, 730-749. https://doi.org/10.1108/LODJ-10-2014-0197

Selznick, P. (1984). Leadership in Administration. Berkeley, CA: University of California Press (Originally Published 1957).

Shin, S. J., \& Zhou, J. (2003). Transformational Leadership, Conservation, Creativity: Evidence from Korea. Academy of Management Journal, 46, 703-714. https://doi.org/10.5465/30040662

Si, S., \& Wei, F. (2012). Transformational and Transactional Leaderships, Empowerment Climate, and Innovation Performance: A Multilevel Analysis in the Chinese Context. European Journal of Work and Organizational Psychology, 21, 299-320. https://doi.org/10.1080/1359432X.2011.570445

Tierney, P., Farmer, S. M., \& Graen, G. B. (2010). An Examination of Leadership and Employee Creativity: The Relevance of Traits and Relationships. Personnel Psychology, 52, 591-620. https://doi.org/10.1111/j.1744-6570.1999.tb00173.x

Wang, P., \& Rode, J. C. (2010). Transformational Leadership and Follower Creativity: The Moderating Effects of Identification with Leader and Organizational Climate. Human Relations, 63, 1105-1128. https://doi.org/10.1177/0018726709354132

Wei, Q. J. (2012). Integrating Creativity and Leadership: Creative Leadership. Journal of Psychological Science, No. 4, 937-942. 